\title{
Clinical Predictors of Health-Related Quality of Life Depend on Asthma Severity
}

\section{Citation}

Moy, M.L., E. Israel, S.T. Weiss, E.F. Juniper, L. Dubé, and J. M. Drazen. 2001. Clinical Predictors of Health-related Quality of Life Depend on Asthma Severity. American Journal of Respiratory and Critical Care Medicine 163, no. 4: 924-29.

\section{Published Version}

10.1164/ajrccm.163.4.2008014

\section{Permanent link}

http://nrs.harvard.edu/urn-3:HUL.InstRepos:42638970

\section{Terms of Use}

This article was downloaded from Harvard University's DASH repository, and is made available under the terms and conditions applicable to Other Posted Material, as set forth at http:// nrs.harvard.edu/urn-3:HUL.InstRepos:dash.current.terms-of-use\#LAA

\section{Share Your Story}

The Harvard community has made this article openly available.

Please share how this access benefits you. Submit a story.

\section{Accessibility}




\title{
Clinical Predictors of Health-related Quality of Life Depend on Asthma Severity
}

\author{
MARILYN L. MOY, ELLIOT ISRAEL, SCOTT T. WEISS, ELIZABETH F. JUNIPER, LOUISE DUBÉ, JEFFREY M. DRAZEN \\ and the NHLBI Asthma Clinical Research Network \\ Division of Pulmonary and Critical Care Medicine and Channing Laboratory, Department of Medicine, Brigham and Women's Hospital and \\ Harvard Medical School, Boston, Massachusetts; Department of Clinical Epidemiology and Biostatistics, McMaster University Medical Center, \\ Hamilton, Ontario, Canada; and Abbott Laboratories, Abbott Park, Illinois
}

\begin{abstract}
The National Asthma Education and Prevention Program guidelines define asthma severity before treatment by lung function and symptoms. It has been assumed, but not demonstrated, that improvement in these measures would translate into improvement in health-related quality of life (HRQL). Because HRQL is an important outcome in asthma management, we asked what are the determinants of HRQL? To address this question, we retrospectively analyzed HRQL data, as measured by the Juniper Asthma Quality of Life Questionnaire, in subjects with mild versus moderate-severe asthma from two clinical trials. We examined whether these traditional clinical outcomes have different relationships to HRQL depending on asthma severity. We also assessed whether the relationship between clinical outcomes and HRQL in subjects with moderate-severe asthma would change when subjects improved to mild-moderate disease with controller medication treatment. Lung function was not an independent predictor or determinant of HRQL at any level of asthma severity, whereas intensity of shortness of breath predicted HRQL at all levels of asthma severity. Rescue $\beta$-agonist use independently predicted HRQL in subjects with mild asthma, but not in those with moderate-severe asthma. In subjects with moderate-severe asthma who improved to mild-moderate disease with controller treatment, rescue $\beta$-agonist use predicted HRQL. We conclude that the independent determinants of $H R Q L$ vary according to asthma severity and change with asthma treatment.
\end{abstract}

One of the primary goals in the treatment of obstructive lung disease is to improve the health-related quality of life (HRQL) of patients. With the advent of valid, reliable, and responsive questionnaires designed to measure HRQL (1-5), it has been shown that traditional clinical parameters such as lung function that focus on airflow obstruction have variable strengths of association with HRQL even though the primary pathobiology of the disease condition is airway obstruction. It has been hypothesized that complex entities such as adverse effects from medication use, anxiety and depression, and patient satisfaction with care are captured by HRQL measurements, but not by conventional physiological and clinical outcomes. These findings have lead to the recommendation that HRQL should be measured as an independent outcome (1-3).

Nevertheless, outcomes of efficacy and effectiveness in asthma clinical trials and in clinical practice have focused on improvement in asthma control, as measured by $\mathrm{FEV}_{1}$ and peak flow, symptom scores, and requirement for the use of reliever medication, with little attention to HRQL (6-9). In fact, the National Asthma Education and Prevention Program

\footnotetext{
(Received in original form August 3, 2000 and in revised form January 3, 2001) Supported by Grant HL07427 from the National Heart, Lung, and Blood Institute. Correspondence and requests for reprints should be addressed to Jeffrey M. Drazen, M.D., Division of Pulmonary and Critical Medicine, Tower 4B, Brigham and Women's Hospital, 75 Francis Street, Boston, MA 02115. E-mail: jdrazen@rics. bwh.harvard.edu

Am J Respir Crit Care Med Vol 163. pp 924-929, 2001

Internet address: www.atsjournals.org
}

(NAEPP) defines asthma severity before treatment by lung function and symptoms; it does not include HRQL $(10,11)$. It has been assumed, but never demonstrated, that improvement in these measures of asthma would translate into improvements in HRQL. Because of the importance of improving HRQL, we asked what are the determinants of HRQL?

We compared HRQL, as assessed by the Juniper Asthma Quality of Life Questionnaire, in subjects with mild asthma and with moderate-severe asthma using clinical guidelines for asthma severity. We identified which traditional physiological and clinical parameters were independent determinants of HRQL in a cross-sectional analysis of entry clinical trial data from these two cohorts of patients. We examined whether the determinants of HRQL differed depending on asthma severity. We also assessed whether the independent predictors of HRQL in the subjects with moderate-severe asthma changed as a result of chronic controller treatment when the subjects' asthma improved to the level of mild-moderate disease.

\section{METHODS}

\section{Patient Selection}

We retrospectively examined data from two completed and reported clinical trials, one in patients with mild asthma (Albuterol Study) (12) and one in patients with moderate-severe asthma (Zileuton Study) (13). In these studies at baseline, patients completed the Juniper Asthma Quality of Life Questionnaire (AQLQ) (1) and recorded symptoms and self-measured peak flows in a diary on a daily basis. The clinical parameters of interest-peak flow, symptoms, and rescue $\beta$-agonist use-were averaged over the $2 \mathrm{wk}$ preceding the assessment of HRQL in order to coincide with the 2-wk recall period of the AQLQ. FEV ${ }_{1}$ and HRQL were assessed at each study visit. All variables were also assessed at the end of the Zileuton Study after controller therapy.

Albuterol Study. These data were from 253 subjects with mild asthma who participated in the multicenter study of the National Heart, Lung, and Blood Institute's Asthma Clinical Research Network comparing regularly scheduled use of albuterol with as-needed use of albuterol. Subjects were recruited from five sites across the United States between 1994 and 1995 . The subjects, 12 to $55 \mathrm{yr}$ of age, had $\mathrm{FEV}_{1} \geqslant 70 \%$ of predicted at enrollment, a $\mathrm{PC}_{20}$ for methacholine of $\leqslant 16 \mathrm{mg} / \mathrm{ml}$, and had not used corticosteroids (inhaled or oral) for the preceding $6 \mathrm{wk}$. Subjects could not have smoked in the past year, and ex-smokers were included only if they had less than a 5 pack-year smoking history.

Zileuton Study. These data were from 395 adults with moderatesevere asthma who were enrolled in a multicenter safety and efficacy study of zileuton in the United States sponsored by Abbott Pharmaceuticals. Subjects were enrolled from private practice offices and university hospital clinics across the United States between 1994 and 1995. These patients had a $\mathrm{FEV}_{1}$ upon entry of 40 to $80 \%$ of their predicted value. To exclude the possibility of misclassification of emphysema for asthma, evidence of reversibility of airflow obstruction with a $15 \%$ increase in $\mathrm{FEV}_{1}$ after inhaled albuterol was documented. Exclusion criteria included current cigarette smoking or history of greater than 10 pack-years of smoking, hospitalization for asthma once within the previous month or more than once within the previous $6 \mathrm{mo}$, or 
treatment with systemic or inhaled corticosteroids within the 4 wk prior to enrollment. Confounding by temporal or geographic differences between the two cohorts is unlikely given that the studies were done at approximately the same time and included subjects from across the United States.

The definition of mild or moderate-severe asthma was further refined using clinical criteria similar to the NAEPP guidelines (10). We defined subjects as having moderate-severe asthma if they satisfied at least one of the following criteria: $\mathrm{FEV}_{1} \%$ predicted $<80 \%$, symptom intensity score for shortness of breath $>1$ (mild symptoms), or number of rescue puffs of $\beta$-agonist use more than four a day. On the basis of this definition, 92 of the 253 subjects in the Albuterol Study had moderate-severe asthma and were excluded from the analysis, leaving 161 subjects with mild asthma in the analyses. Four of the 395 subjects in the Zileuton Study had mild asthma and were excluded from the analysis.

The two trials had been approved by the appropriate institutional committees on human research, and written informed consent had been obtained from each patient.

\section{Health-related Quality of Life}

The Juniper AQLQ was used to assess HRQL in both studies. This instrument is an asthma-specific questionnaire with 32 items that provides an Overall Summary Index and assesses four domains of HRQL - activity limitation, symptoms, emotional function, and environmental exposures during the preceding $2 \mathrm{wk}$ (1). The response options for each of the 32 items are on a 7-point Likert scale, ranging from 1 (totally limited) to 7 (not at all limited). The AQLQ has been shown to be sensitive to change in HRQL; a change score of 0.5 points has been determined to be the minimal important difference (14).

The AQLQ was designed and has been shown to (1) reflect areas of function that are important to adults with asthma, (2) include both physical and emotional function, (3) be reproducible when the clinical state is stable, and (4) be responsive to changes that are important to the patient even if the changes are small (15). Although it was designed to be an evaluative instrument that would be sensitive to small within-subject changes over time, with responsiveness to change and longitudinal construct validity, it has also been shown to be a valid and reliable discriminative instrument that distinguishes among patients with asthma in cross-sectional surveys (15).

\section{Pulmonary Function Measurements}

$\mathrm{FEV}_{1}$, FVC, and peak flow were measured in both studies using equipment that met ATS criteria (16). The best of three spirometric measurements, obtained after $\beta$-agonists were withheld for at least $8 \mathrm{~h}$, with patients in a sitting position, was recorded for evaluation. This recording obtained at the study visit was used in the analyses. Morning (AM $\mathrm{PF}$ ) and evening (PM PF) peak flow values were recorded at home every $24 \mathrm{~h}$ with a Mini-Wright peak-flow meter (Clement Clarke, Columbus, $\mathrm{OH})$. Readings were taken in triplicate and recorded by the patients in their diaries. The best of three efforts was recorded. An average of the peak flow readings during the 2 wk preceding the study visit was used in the analyses.

\section{Symptoms and Rescue $\boldsymbol{\beta}$-agonist Use}

In both studies, symptoms of wheeze, shortness of breath, chest tightness, and cough were recorded once daily with the use of diary cards. The symptom severity rating scale was defined as follows: 0 : absent, no symptoms; 1 : mild, symptom was minimally troublesome (not sufficient to interfere with normal daily activity or sleep); 2: moderate, symptom was sufficiently troublesome to interfere with normal daily activity or sleep; 3: severe, symptom was so severe as to prevent normal activity and/or sleep. Symptom intensity was assessed independently since it has been shown that symptom intensity does not correlate with the "Symptom" domain of the AQLQ which assesses the impact of symptoms on HRQL $(17,18)$. The symptom intensity scores were averaged during the 2 wk preceding the study visit and used in the analyses.

Open-label inhaled albuterol sulfate was the only asthma medication allowed other than the study drug during the trials; subjects were allowed to use albuterol on an as-needed basis. All patients were instructed on the importance of recording each use of albuterol throughout the study, entering the time of each albuterol use and the number of puffs per occasion. The number of rescue puffs of $\beta$-agonist was recorded on a daily basis in the diaries; an average for the $2 \mathrm{wk}$ preceding the study visit was used in the analyses.

\section{Statistical Analysis}

Analyses were performed on baseline data obtained before randomized treatment in both the mild asthma and the moderate-severe asthma cohorts. We also examined final data from subjects with moderate-severe asthma who had improved their $\mathrm{FEV}_{1}$ at least $5 \%$ at the end of the controller treatment period when compared with their baseline values. Results from these cross-sectional final data in the moderate-severe asthma study were compared with those from the cohort of subjects with mild asthma at baseline.

Wilcoxon's nonparametric rank sum test was used to assess differences between groups of subjects in the mild asthma study and the moderate-severe asthma study. Univariate correlations between the continuous variables and HRQL were assessed by Spearman's correlation coefficients. Linear regression analyses with multivariate models were used to assess the independent relationship of each clinical parameter with HRQL (19). These models adjusted for age and sex given their potential to modify the relationship between the clinical variables and HRQL. Only the results from models using the Overall AQLQ score as the outcome are reported; results from analyses using each of the four domains of the AQLQ as outcomes are not shown.

All analyses were performed using the SAS statistical software package (SAS Institute, Cary, NC). Significance was defined as $\mathrm{p} \leqslant$ 0.05 . Model diagnostics showed that morning and evening peak flow values were collinear. Only morning peak flow was included in the regression models. There were no outliers and influential points, and linear regression model assumptions were examined and satisfied.

\section{RESULTS}

Of the patients with mild asthma, $58 \%$ were women (mean age, $28 \pm 9 \mathrm{yr})$. Mean $\mathrm{FEV}_{1}$ was $3.31 \pm 0.64 \mathrm{~L}(96 \pm 10 \%$ of predicted values) and mean ratings of patient-reported symptoms were between 0 (no symptoms) and (minimally troublesome symptoms) (Table 1). Of the cohort of subjects with moderate-severe airflow obstruction, $53 \%$ were women (mean age, $32 \pm 10 \mathrm{yr})$. Mean $\mathrm{FEV}_{1}$ was $2.26 \pm 0.64 \mathrm{~L}(60 \pm 12 \%$ of predicted values), and symptom intensity scores ranged from 0.69 for cough to 1.22 for shortness of breath. The average number of puffs of rescue $\beta$-agonist used per day was more than eight times higher in the cohort of subjects with moderate-severe asthma (5.83 puffs/d) than in the group of subjects with mild airway obstruction $(0.68 \mathrm{puffs} / \mathrm{d})(\mathrm{p}<0.0001)$.

Across all domains, HRQL scores were significantly better in the cohort of subjects with mild asthma than in those with moderate-severe asthma (Table 1). For the subjects with mild asthma, mean HRQL scores ranged between 5 (a little limitation) and 4 (some limitation), from 4.94 for the "Activities" domain to 4.68 for the "Environment" domain. For subjects with moderate-severe asthma, mean HRQL scores ranged from 4.42 for the "Activities" domain to 3.93 for the "Emotions" domain. There was no ceiling or floor effect in measuring HRQL with the AQLQ in the two study populations. The mean baseline score for each domain of the AQLQ in the group of patients with moderate-severe asthma in whom change with treatment was evaluated was 3.93 to 4.42 . Plotting the range of HRQL scores shows a wide distribution across the entire scoring range from 1 to 7 . There was adequate room to register a change of 0.5 , which is the minimal important clinical difference, after treatment, before reaching the maximum score of 7 or the minimum score of 1 .

The wide range of HRQL Overall scores for a given lung function in subjects with moderate-severe asthma is shown in Figure 1. Subjects with \% predicted $\mathrm{FEV}_{1}$ between 40 and 60 had HRQL scores ranging from 1.3 to 6.6. Furthermore, it can 
TABLE 1. CHARACTERISTICS OF PATIENTS IN EACH STUDY GROUP*

\begin{tabular}{lccc}
\hline Characteristic & $\begin{array}{c}\text { Albuterol Study } \\
(n=161)\end{array}$ & $\begin{array}{c}\text { Zileuton Baseline } \\
(n=391)\end{array}$ & $\begin{array}{c}\text { Zileuton Final }^{\dagger} \\
(n=127)\end{array}$ \\
\hline Age, yr & $28 \pm 9$ & $32 \pm 10$ & $32 \pm 10^{\dagger \dagger}$ \\
Sex, \% male & 42 & $47^{\mathrm{NS}}$ & $53^{\mathrm{NS}}$ \\
FEV, $\mathrm{L}$ & $3.31 \pm 0.64$ & $2.26 \pm 0.64$ & $2.73 \pm 0.72$ \\
$\mathrm{FEV}, \%$ pred & $96 \pm 10$ & $60 \pm 12$ & $72 \pm 14$ \\
$\mathrm{FVC}, \mathrm{L}$ & $4.28 \pm 0.87$ & $3.39 \pm 1.01$ & $3.86 \pm 1.04^{\dagger \dagger}$ \\
FVC, \% pred & $106 \pm 11$ & $76 \pm 14$ & $101 \pm 14^{\dagger+\dagger}$ \\
AM peak flow, L/min & $441 \pm 98$ & $367 \pm 93$ & $393 \pm 98^{\dagger \dagger}$ \\
PM peak flow, L/min & $453 \pm 96$ & $412 \pm 97$ & $442 \pm 100^{\mathrm{NS}}$ \\
Rescue use of $\beta$-agonists, puffs & $0.68 \pm 0.91$ & $5.83 \pm 2.80$ & $4.06 \pm 2.96$ \\
Patient-reported symptoms & & & \\
$\quad$ Shortness of breath & $0.31 \pm 0.35$ & $1.22 \pm 0.59$ & $0.74 \pm 0.55$ \\
$\quad$ Wheeze & $0.28 \pm 0.34$ & $1.05 \pm 0.63$ & $0.60 \pm 0.56$ \\
$\quad$ Cough & $0.26 \pm 0.35$ & $0.69 \pm 0.64$ & $0.38 \pm 0.54^{\mathrm{NS}}$ \\
HRQL Scores & & & \\
$\quad$ Symptoms & $4.78 \pm 0.77$ & $3.98 \pm 1.01$ & $4.96 \pm 1.05^{\mathrm{NS}}$ \\
$\quad$ Activities & $4.94 \pm 0.75$ & $4.42 \pm 0.99$ & $5.19 \pm 1.01^{\dagger+\dagger}$ \\
$\quad$ Emotions & $4.85 \pm 1.00$ & $3.93 \pm 1.42$ & $4.93 \pm 1.34^{\mathrm{NS}}$ \\
$\quad$ Environment & $4.68 \pm 1.13$ & $4.00 \pm 1.29$ & $4.88 \pm 1.16^{\mathrm{NS}}$ \\
$\quad$ Overall & $4.83 \pm 0.74$ & $4.12 \pm 0.96$ & $5.02 \pm 0.98^{\dagger \dagger \dagger}$ \\
\hline
\end{tabular}

Definition of abbreviations: $\mathrm{AM}=$ morning; $\mathrm{HRQL}=$ health-related quality of life; $\mathrm{PM}=$ evening.

* All characteristics, except FEV, FVC, and HRQL scores (measured at each visit), are averaged over the 2 wk preceding the HRQL assessment. Plus-minus values are means \pm SD.

† Statistical analysis by Wilcoxon's rank sum test; $p$ value is for between-group comparison of the response in the Albuterol study and in the Zileuton study at baseline. All $p<0.0001$ except when noted (NS = not significant).

¥ Statistical analysis by Wilcoxon's rank sum test; $p$ value is for between-group comparison of the response in the Albuterol study and in the Zileuton study at the end of the controller treatment period for those subjects who improved $\mathrm{FEV}_{1}$ at least $5 \% ; \mathrm{p}<0.0001$ except when noted $\left({ }^{\dagger \dagger} \mathrm{p}<0.0005 ;{ }^{\dagger \dagger \dagger} \mathrm{p}<0.05 ; \mathrm{NS}=\right.$ not significant).

$\S$ Asthma symptoms were graded by the subject each day, from 0 for no symptoms to 3 for severe symptoms.

" Juniper Asthma Quality of Life Questionnaire was completed by the subject at baseline and at end of treatment. A score of 7.0 indicates that asthma had no effect on HRQL; a score of 6.0 indicates that the patient was "a little limited" by asthma; a score of 4.0 indicates that there was "some limitation"; and a score of 1.0 indicates that there was "total limitation."

be seen in Figure 1 that HRQL in subjects with mild asthma correlated better with lung function with less of a spread in the range of HRQL scores. $\mathrm{FEV}_{1} \%$ predicted, FVC, and $\mathrm{FVC} \%$ predicted were weakly and not significantly correlated with HRQL in both studies and were not included in the multivariate analyses.

\section{Determinants of HRQL in Subjects with Mild Asthma}

All parameters- $\mathrm{FEV}_{1}$, peak flow, rescue puffs $\beta$-agonist, and symptoms-were significantly correlated with the Overall HRQL score in the subjects with mild asthma. The strength of association between the intensity of shortness of breath and reliever medication use and HRQL was greater than that between $\mathrm{FEV}_{1}$ and $\mathrm{HRQL}(\mathrm{r}=0.56$ and 0.49 versus 0.18$)$ (Table 2). In the subjects with mild asthma, after adjusting for age, sex, and clinical parameters, multivariate linear regression analysis demonstrated that measures of lung function did not predict HRQL (Table 3). In these patients, rescue puffs of $\beta$-agonist and symptom intensity of shortness of breath, wheeze, and cough were significant predictors of HRQL.

\section{Determinants of HRQL in Subjects with Moderate-Severe Asthma}

In subjects with moderate-severe asthma, $\mathrm{FEV}_{1}$ and number of puffs of $\beta$-agonist use did not correlate significantly with HRQL, and the strength of the association between symptom intensity and HRQL was reduced in this cohort compared with that in the subjects with mild asthma $(r=0.21$ to 0.27 versus 0.34 to 0.56 ). In the subjects with moderate-severe asthma, only symptom intensity of shortness of breath and cough independently predicted HRQL. In a comparison of the two studies, the clinical parameters of lung function, symptoms, and rescue $\beta$-agonist use accounted for a greater percentage of the variance in HRQL in the subjects with mild asthma than in the cohort of moderate-severe asthmatics (model $\mathrm{R}^{2}=0.40$ compared with 0.12).

When the 92 patients from the Albuterol trial who met the definition of moderate-severe asthma were analyzed alone or merged with the Zileuton baseline cohort of moderate-severe asthmatics, $\mathrm{FEV}_{1}$ and rescue $\beta$-agonist use were not associated with HRQL, whereas symptom of shortness of breath was associated with HRQL. These findings were unchanged from the analyses of the moderate-severe Zileuton baseline cohort alone. The same result in this cohort of patients with moderate-severe asthma (from the Albuterol study) serves as a "sensitivity analysis" and further substantiates the results found in the Zileuton study. The patients of the Albuterol study were not incorporated into the Zileuton study because they did not receive controller medication and no post treatment data were obtained.

Relationship between HRQL and Clinical Parameters in Those Moderate-Severe Subjects who Improved to Mild-Moderate Asthma after Zileuton Controller Therapy

Of the subjects with moderate-severe asthma at baseline, $49 \%$ increased their $\mathrm{FEV}_{1}$ at least $5 \%$ in response to treatment with zileuton. In this group, mean peak flow values, rescue puffs of $\beta$-agonist, symptom intensity scores, and HRQL scores improved such that their values at the end of the study were within the range of that seen in the subjects with mild asthma (Table 1). Among these subjects, all parameters, except FEV , were significantly correlated with HRQL, and the strength of the correlations was similar to that seen in the subjects at baseline with mild asthma (Table 2). Although $\mathrm{FEV}_{1}$ was not significantly correlated with HRQL, the strength of the association was similar to that seen in the subjects with mild asthma $(\mathrm{r}=0.18)$ and tended towards significance $(\mathrm{r}=0.16, \mathrm{p}=0.06)$. In these subjects, multivariate linear regression models showed 


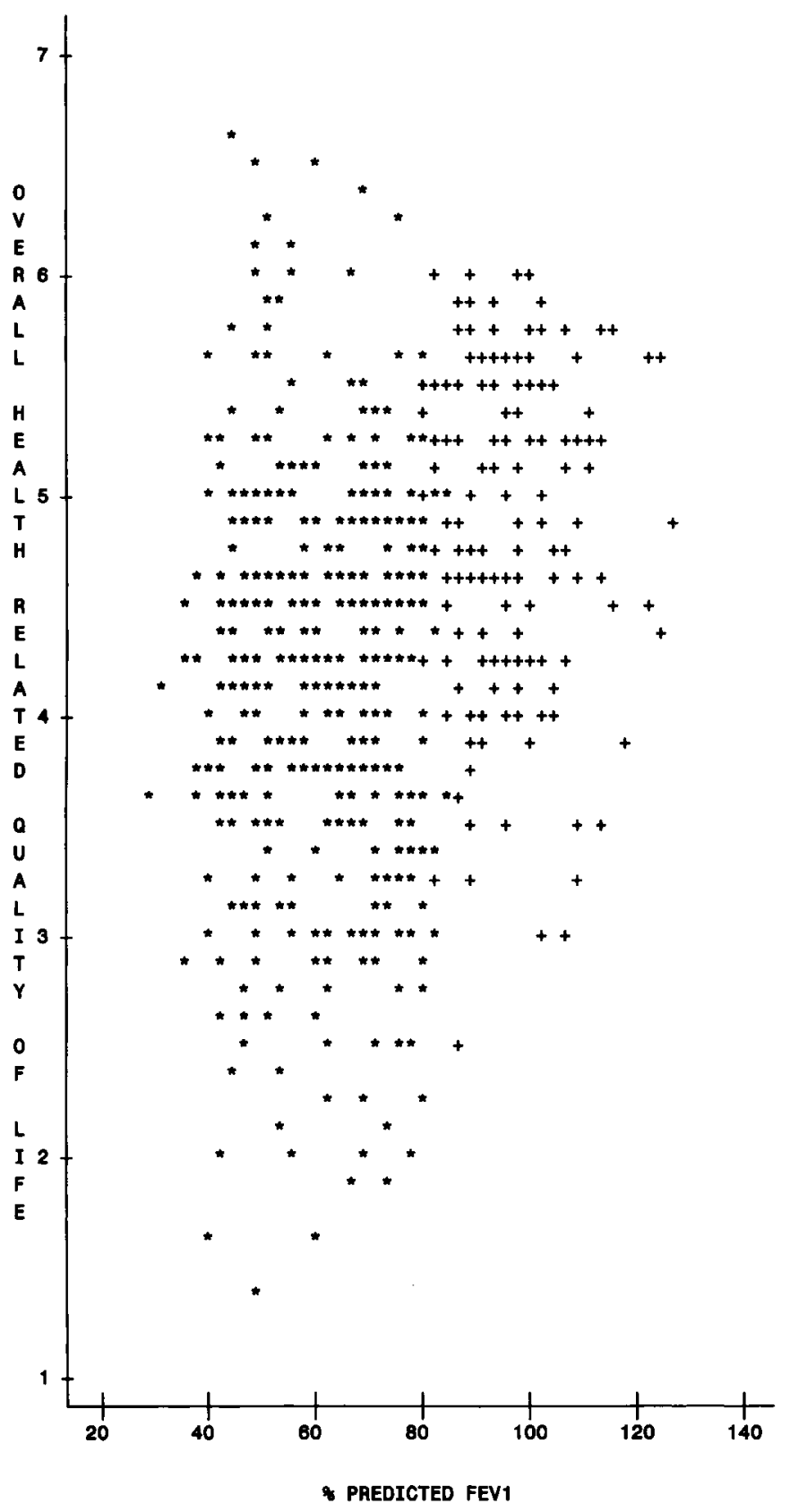

Figure 1. In subjects with moderate-severe asthma $\left({ }^{*}\right)$, there is a wide range of $\mathrm{HRQL}$ Overall scores for a given \% predicted $\mathrm{FEV}_{1}, \mathrm{r}=0.06$. Note that subjects with \% predicted $\mathrm{FEV}_{1}$ between 40 and 60 had HRQL Overall scores ranging from 1.3 to 6.6. In subjects with mild asthma $(+)$, there is a greater strength of association between HRQL overall score and \% predicted $\mathrm{FEV}_{1}, \mathrm{r}=0.18$, and less of a range in $\mathrm{HRQL}$ for a given lung function.

that rescue puffs of $\beta$-agonist and intensity of shortness of breath were significant independent predictors of HRQLfindings similar to those among the subjects with mild asthma (Table 3). Furthermore, the model $\mathrm{R}^{2}$ of 0.48 was similar to that seen in the subjects with mild asthma $\left(\mathrm{R}^{2}=0.40\right)$.

In the subset of patients who did not improve their $\mathrm{FEV}_{1}$ at least $5 \%$ in response to treatment with zileuton, multivariate regression analysis showed that symptom intensity of shortness of breath and wheeze were the independent determinants of HRQL, a finding similar to that seen in the baseline cohort
TABLE 2. UNIVARIATE CORRELATIONS WITH HRQL OVERALL SCORE BY ASTHMA SEVERITY*

\begin{tabular}{|c|c|c|c|c|c|c|}
\hline \multirow[b]{2}{*}{ Variable $^{\dagger}$} & \multicolumn{2}{|c|}{$\begin{array}{l}\text { Albuterol } \\
\text { Baseline } \\
(n=161)\end{array}$} & \multicolumn{2}{|c|}{$\begin{array}{c}\text { Zileuton } \\
\text { Baseline } \\
(n=391)\end{array}$} & \multicolumn{2}{|c|}{$\begin{array}{c}\text { Zileuton } \\
\quad \text { Final } \\
(n=127)\end{array}$} \\
\hline & $\mathrm{r}$ & $\mathrm{p}$ Value & $\mathrm{r}$ & $\mathrm{p}$ Value & $\mathrm{r}$ & $\mathrm{p}$ Value \\
\hline $\mathrm{FEV}_{1}$ & 0.18 & 0.02 & 0.06 & NS & 0.16 & 0.06 \\
\hline AM peak flow & 0.18 & 0.02 & 0.13 & 0.01 & 0.22 & 0.01 \\
\hline PM peak flow & 0.20 & 0.01 & 0.13 & 0.01 & 0.17 & 0.05 \\
\hline Rescue puffs $\beta$-agonist & -0.49 & 0.0001 & -0.06 & NS & -0.49 & 0.0001 \\
\hline Symptom, $\mathrm{SOB}^{\ddagger}$ & -0.56 & 0.0001 & -0.25 & 0.0001 & -0.63 & 0.0001 \\
\hline Wheeze & -0.50 & 0.0001 & -0.21 & 0.0001 & -0.33 & 0.0002 \\
\hline Cough & -0.34 & 0.0001 & -0.27 & 0.0001 & -0.35 & 0.0001 \\
\hline
\end{tabular}

Definition of abbreviations: $\mathrm{AM}=$ morning; $\mathrm{NS}=$ not significant; $\mathrm{PM}=$ evening; $\mathrm{R}=$ correlation coefficient; SOB = shortness of breath.

* Statistical analysis by Spearman's correlations.

$\dagger$ All variables, except FEV 1 (measured at each visit), are averaged over the 2 wk preceding the HRQL assessment.

¥ See the footnotes to Table 1 for an explanation of the scoring system.

of subjects with moderate-severe asthma. In this group of patients who continued to have moderate-severe asthma despite controller medication use, reliever medication use was not an independent predictor of HRQL. Of note, the independent predictors of HRQL were the same in both the responder and the nonresponder groups at baseline, as in the entire baseline cohort with moderate-severe asthma, and only the latter results are shown.

\section{DISCUSSION}

These studies have demonstrated that the independent determinants or predictors of HRQL, in the absence of treatment intervention, differ as a function of the severity of asthma under consideration. More importantly, we have shown that the correlates of HRQL change as a result of asthma treatment. The intensity of asthma symptoms consistently predicted HRQL in both severity groups, whereas reliever medication use predicted HRQL only in those subjects with mild asthma. After adjusting for symptom intensity and reliever medication use, lung function was not an independent predictor of HRQL at all asthma severity.

The results of this study show that asthma severity, defined by lung function, symptoms, and reliever medication use, correlates with HRQL as measured by the Juniper AQLQ. Subjects with moderate-severe asthma had worse HRQL compared with those patients with mild asthma. Although conventional clinical parameters correlate with and independently predict HRQL, it is important to acknowledge that the strength of the association is quite low. The cross-sectional correlations between clinical parameters and HRQL observed in this study are similar to those reported in the literature $(15$, 17, 18, 20-22).

There was a wide range of HRQL scores for a given level of lung function (Figure 1). This finding presumably reflects differences in adaptation to limitations, temperament and motivation, psychosocial and economic support, and access to healthcare in patients with asthma and the extent to which patients' perception of their asthma varies and/or has adapted with time. Symptom intensity score and reliever medication use are more strongly correlated than lung function with HRQL scores in both cross-sectional and longitudinal analyses using the AQLQ $(17,18)$. It is possible that the $\mathrm{FEV}_{1}$ was not more strongly correlated with HRQL because $\mathrm{FEV}_{1}$ represents one time point, whereas HRQL represents an average over the preceding $2 \mathrm{wk}$, as do the symptom scores and reliever medi- 
TABLE 3. PREDICTORS OF OVERALL HRQL BY ASTHMA SEVERITY*

\begin{tabular}{|c|c|c|c|c|c|c|}
\hline & $\begin{array}{c}\text { Albutero } \\
\text { Baseline } \\
(n=161 \\
\text { Variable }\end{array}$ & & $\begin{array}{c}\text { Zileuton } \\
\text { Baseline } \\
(n=391 \\
\text { Variable }\end{array}$ & & $\begin{array}{c}\text { Zileuton } \\
\text { Final }^{\S} \\
(n=127 \\
\text { Variable }\end{array}$ & \\
\hline & $\begin{array}{l}\text { Adjusted } \\
\text { Parameter } \\
\text { Estimate } \\
\text { (SE) }\end{array}$ & $\mathrm{p}$ Value & $\begin{array}{l}\text { Adjusted } \\
\text { Parameter } \\
\text { Estimate } \\
\text { (SE) }\end{array}$ & $p$ Value & $\begin{array}{l}\text { Adjusted } \\
\text { Parameter } \\
\text { Estimate } \\
\text { (SE) }\end{array}$ & p Value \\
\hline $\mathrm{FEV}_{1}$ & $0.076(0.12)$ & NS & $-0.094(0.11)$ & NS & $0.184(0.13)$ & NS \\
\hline AM peak flow & $-0.0006(0.001)$ & NS & $0.0003(0.001)$ & NS & $-0.0003(0.001)$ & NS \\
\hline Rescue puffs $\beta$-agonist & $-0.1393(0.06)$ & 0.02 & $-0.0057(0.02)$ & NS & $-0.0651(0.02)$ & 0.01 \\
\hline Symptom ${ }^{*}$ SOB & $-0.751(0.16)$ & 0.0001 & $-0.200(0.09)$ & 0.03 & $-0.858(0.15)$ & 0.0001 \\
\hline Wheeze & $-0.376(0.18)$ & 0.03 & $-0.169(0.09)$ & NS & $-0.026(0.14)$ & NS \\
\hline Cough & $-0.315(0.15)$ & 0.04 & $-0.239(0.08)$ & 0.005 & $-0.282(0.14)$ & 0.05 \\
\hline
\end{tabular}

Definition of abbreviations: NS = not significant; SE = standard error; SOB = shortness of breath.

* Statistical analysis by multivariate linear regression. Models adjust for age, sex, and the variables listed in table.

$\dagger$ Model $R^{2}=0.4052$

† Model $R^{2}=0.1197$

$\S$ Model $\mathrm{R}^{2}=0.4839$.

" All variables, except $\mathrm{FEV}_{1}$ (measured at each visit), are averaged over the $2 \mathrm{wk}$ preceding the HRQL assessment.

I See the footnotes to Table 1 for an explanation of the scoring system.

cation use. However, arguing against this is the fact that peak flow values, also averaged over the preceding $2 \mathrm{wk}$, were not independent predictors of HRQL in the regression models. Therefore, these conventional clinical parameters should not be used in place of measuring HRQL directly. Furthermore, in all models, the traditional clinical and physiological parameters of lung function, symptom intensity, and use of reliever medication, at most, accounted for less than half of the variation in HRQL. These findings are in agreement with a principal component analysis reported by Wisniewski and colleagues (23) who demonstrated that HRQL, clinical parameters, daytime patient-rated symptoms, and nighttime patient-rated symptoms measured distinct dimensions of asthma. These findings add further support to the recommendation that HRQL should be measured in addition to conventional clinical parameters.

The findings of this study have implications on what parameters should be used to define cohorts of asthmatics in clinical trials when HRQL is an outcome of interest. We argue that $\mathrm{FEV}_{1}$ alone should not be used to define subjects with mild versus those with moderate-severe asthma, but that baseline HRQL should be an additional criterion. By extension, we propose that $\mathrm{FEV}_{1}$ alone should not be used to assess the HRQL of groups of patients in clinical practice. It should not be assumed that the HRQL is poor if lung function itself is reduced or that HRQL has improved in response to treatment based on the fact that lung function alone has improved. A value in $\%$ predicted $\mathrm{FEV}_{1}$ of $85 \%$ could be normal or could reflect a significant decline if, for example, the patient's best ever value was $125 \%$ predicted. In examining the patients with mild asthma, 21 subjects had \% predicted $\mathrm{FEV}_{1}$ in the "normal" range at baseline and had an increase of greater than 10 percentage points in $\%$ predicted $\mathrm{FEV}_{1}$ at the end of the study. There were 17 subjects within the same range whose $\mathrm{FEV}_{1}$ did not increase 10 percentage points. Thus, the empirically chosen cutoffs for asthma severity defined by $\mathrm{FEV}_{1}$ do not give the whole picture, and need to be coupled with symptoms, reliever medication use, and HRQL. Symptom intensity of shortness of breath, wheeze, and cough are the most consistent and strongest predictors of HRQL, and they need to be independently assessed and considered with lung function.

There is no gold standard to categorize asthma severity. We would propose that HRQL be added to the NAEPP guidelines and be used in conjunction with measures of lung function and symptoms to define asthma severity. Patients would be assigned to the most severe step in which the worst grading for a variable occurs. Furthermore, we propose that population-based studies should examine correlates of asthma outcomes such as HRQL stratified by asthma severity. For example, Vollmer and colleagues (24) showed that reliever medication use significantly predicted the Juniper HRQL summary scale; however, the difference in the parameter estimate between their study and the current study $(-0.4$ versus -0.14$)$ could be explained by the inclusion of all subjects with asthma, regardless of severity, in their analysis.

It is acknowledged that the current findings may not be generalizable to all populations of asthmatics or to the clinical setting, as selection bias may exist in these subjects participating in a clinical trial. For example, subjects were not receiving any inhaled or parenteral corticosteroid therapy. However, these patients were identified as receiving reliever medication alone and provided a unique opportunity to apply clinical definitions of asthma severity, similar to those of the NAEPP, before the use of any controller medications. In order to avoid multiple comparisons and statistically significant correlations by chance alone when examining each of the four domains of AQLQ with the variables of interest, i.e., lung function, reliever mediation use, and symptoms, we chose to assess only the correlations with the Overall summary score. Most, but not all, of the individual domains were reflected by the Overall score.

In conclusion, the conventional clinical parameters of lung function, symptoms, and reliever medication use predict HRQL differently depending on the level of asthma severity under study. Furthermore, these traditional measures of asthma severity and asthma control explain only half of the variance of HRQL. If we are to maximize the ability of our patients to live with their asthma, we need to prospectively delineate the entire array of contributors to HRQL in patients with asthma.

\section{References}

1. Juniper EF, Guyatt GH, Epstein RS, Ferrie PJ, Jaeschke R, Hiller TK. Evaluation of impairment of health related quality of life in asthma: development of a questionnaire for use in clinical trials. Thorax 1992; 47:76-83.

2. Jones PW, Quirk FH, Baveystock CM, Littlejohns P. A self-complete measure of health status for chronic airflow limitation: The St. George's Respiratory Questionnaire. Am Rev Respir Dis 1992;145: 1321-1327. 
3. Ware JE, Sherbourne CA. The MOS 36-item short-form health survey (SF-36): conceptual framework and item selection. Med Care 1992;30: 473-483.

4. Bousquet J, Knani J, Dhivert H, Richard A, Chicoye A, Ware JE Jr, Michel F. Quality of life in asthma: internal consistency and validity of the SF-36 questionnaire. Am J Respir Crit Care Med 1994;149:371-375.

5. Rutten-van Molken MPMH, Custers F, Van Doorslaer EKA, Jansen CCM, Heurman L, Maesen FPV, Smeets JJ, Bommer AM, Raaijmakers JAM. Comparison of performance of four instruments in evaluating the effects of salmeterol on asthma quality of life. Eur Respir $J$ 1995;8:888-898.

6. Pearlman DS, Chervinsky P, LaForce C, Seltzer JM, Southern DL, Kemp JP, Dockhorn RJ, Grossman J, Liddle RF, Yancey SW, et al. A comparison of salmeterol with albuterol in the treatment of mild-tomoderate asthma. N Engl J Med 1992;327:1420-1425.

7. D'Alonzo GE, Nathan RA, Henochowicz S, Morris RJ, Ratner P, Rennard SI. Salmeterol xinafoate as maintenance therapy compared with albuterol in patients with asthma. JAMA 1994;271:1412-1416.

8. Suissa S, Dennis R, Ernst P, Sheehy O, Wood-Daupinee S. Effectiveness of the leukotriene receptor antagonist zafirlukast for mild-to-moderate asthma. Ann Intern Med 1997;126:177-183.

9. Rutten-Van Molken MPMH, Van Doorslaer EKA, Jansen MCC, Kerstjens HAM, Rutten FFH. Costs and effects of inhaled corticosteroids and bronchodilators in asthma and chronic obstructive pulmonary disease. Am J Respir Crit Care Med 1995;151:975-982.

10. National Asthma Education and Prevention Program. Expert Panel Report 2: guidelines for the diagnosis and management of asthma. Bethesda, MD: National Institutes of Health; 1997 Publication No. 974051A.

11. Cockcroft DW, Swystun VA. Asthma control versus asthma severity. $J$ Allergy Clin Immunol 1996;98:1016-1018.

12. Drazen JM, Israel E, Boushey HA, Chinchilli VM, Fahy JV, Fish JE, Lazarus SC, Lemanske RF, Martin RJ, Peters SP, et al. Comparison of regularly scheduled with as-needed use of albuterol in mild asthma. $N$ Engl J Med 1996;335:841-847.

13. Israel E, Cohn J, Dube L, Drazen JM. Effect of treatment with zileuton, a 5-lipoxygenase inhibitor, in patients with asthma. JAMA 1996;275: 931-936.
14. Juniper EF, Guyatt GH, Willan A, Griffith LE. Determining a minimal important change in a disease-specific quality of life questionnaire. $J$ Clin Epidemiol 1994;47:81-87.

15. Juniper EF, Guyatt GH, Ferrie PJ, Griffith LE. Measuring quality of life in asthma. Am Rev Respir Dis 1993;147:832-838.

16. Medical Section of the American Lung Association. Lung function testing: selection of reference values and interpretative strategies. Am Rev Respir Dis 1991;144:1202-1218.

17. Juniper EF, Johnston PR, Borkhoff CM, Guyatt GH, Boulet LP, Haukioja A. Quality of life in asthma clinical trials: comparison of salmeterol and salbutamol. Am J Respir Crit Care Med 1995;151:66-70.

18. Juniper EF, Buist AS, and the Study Group. Health-related quality of life in moderate asthma: $400 \mu \mathrm{g}$ hydrofluoroalkane beclomethasone dipropionate vs $800 \mu \mathrm{g}$ chlorofluorocarbon beclomethasone dipropionate. Chest 1999;116:1297-1303.

19. Kleinbaum DJ, Kupper LL, Muller KE, Nizam A. Applied regression analysis and other multivariable methods, 3rd ed. Boston: Duxbury Press; 1998.

20. Juniper EF, Buist AS, Cox FM, Ferrie PJ, King DR. Validation of a standardized version of the asthma quality of life questionnaire. Chest 1999;115:1265-1270.

21. Juniper EF, Guyatt GH, Cox FM, Ferrie PJ, King DR. Development and validation of the mini asthma quality of life questionnaire. Eur Respir J 1999;14:1038-1043.

22. Juniper EF, Svensson K, O'Byrne PM, Barnes PJ, Bauer C-A, Lofdahl C- GA, Postma DS, Pauwels RA, Tatersfield AE, Ullman A. Asthma quality of life during 1 year of treatment with budesonide with or without formoterol. Eur Respir J 1999;14:1038-1043.

23. Wisniewski M, Emmett A, Petrocella V, Kalberg C, Cox F, Rickard K, Bowers B. Principal component analysis of the asthma quality of life questionnaire (AQLQ) to examine the addition of information to clinical and symptom measures in patients with asthma [abstract]. Am J Respir Crit Care Med 1997;155:A721.

24. Vollmer WM, Markson LE, O’Connor E, Sanocki LL, Fitterman L, Berger M, Buist AS. Association of asthma control with health care utilization and quality of life. Am J Respir Crit Care Med 1999;160: 1647-1652. 